\title{
Chandanadi ghruta tarpana in Computer vision syndrome—A Pilot Study
}

\author{
Research Article
}

\section{Jyoti $\mathbf{S}^{1^{*}}$, Ravindra Angadi ${ }^{2}$, Ramesh $\mathbf{B N}^{3}$}

1. PG Scholar, 3. Associate Professor Professor \& Head,

Department of PG studies in Shalakya Tantra, Govt Ayurvedic Medical College, Bangalore- 560009

2. Associate Professor, Department of P G Studies in RS and BK, SDM College of Ayurveda, Kuthpady, Udupi-574118

\begin{abstract}
Computer vision syndrome, a recent occupational hazard, is a collection of features like 'eye strain', 'blurred vision', 'redness', 'dryness', 'headache', 'diplopia' etc. About 50 to $90 \%$ of the regular computer users are affected with these symptoms. Although a number of researches have been carried out, no curative treatment has been achieved yet. Only palliative measures in the form of tear supplements are available which have to be used lifelong by the patients. Hence, aim of this pilot study is to understand the efficacy of 'chandanadi ghrita tarpana' in computer vision syndrome.
\end{abstract}

Keywords : Chandanadi ghrita, Tarpana

\section{Introduction}

The invention of computer and advancement in information technology has revolutionized and immensely benefited the society but at the same time has caused symptoms related to its usage such as ocular sprain, irritation, redness, dryness, blurred vision and double vision.

This cluster of symptoms is known as "computer vision syndrome" which is characterized by the visual symptoms which result from interaction with computer display or its environment.(1)

Since computer use is such a visually demanding task, vision problems and symptoms have become very common in today's work place. Most studies indicate that computer operators who view their video display terminals (VDT) report more eye related problems than non VDT office workers.

NIOSH Survey (National Institute of Occupational Safety and Health) has reported that visual symptoms occur in $75-90 \%$ of VDT workers as opposed to $22 \%$ of musculoskeletal disorders (carpel tunnel syndrome) in computer users.(2)

The American Optometric Association (AOA) defines computer vision syndrome as "Complex of eye and vision problems related to near work, which are experienced during or related to computer use, like dry eyes, eye strain, neck and / or back pain, light sensitivity and fatigue, red eyes, burning eyes, inability to focus near objects". These symptoms can result from individual visual problems, poor work station configuration and improper work habits.(3)

\section{*Corresponding Author:}

\section{Jyoti S}

Department of PG studies in Shalakya Tantra,

Govt Ayurvedic Medical College, Bangalore- 560009

Mobile No. +91-9449330827

E-mail: drjyotiravindra@gmail.com

\section{Objectives of the study}

To know the efficacy of "chandanadi ghrita tarpana, ${ }^{4}$ in the management of 'Computer vision syndrome'.

\section{Materials and methods \\ Source of data:}

The patients with signs and symptoms of 'computer vision syndrome' were selected from OPD and IPD of 'Shalakya Tantra' of Sri Jayachamarajendra Institute of Indian Medicine, Bangalore.

\section{Methods of collection of data}

The selection was done on the basis of clinical examination. A careful clinical history of all those patients complaining of 'eye strain', 'blurred vision', 'redness', 'dryness', 'headache', 'diplopia' - with 3 or more symptoms were considered. After thorough examination and establishment of the diagnosis, the patients were taken for the clinical study.

\section{Inclusion criteria and exclusion criteria}

Patients between 16 to 70 years of age who regularly use computer for a minimum 4 hours a day and have used it for a minimum of 6 months continuously; who have the complaints of eye strain, dry eyes, headache, blurred vision, diplopia, redness and progressive refractive changes with 3 or more features are included for the study.

Patients suffering from infectious conditions of the eye like conjunctivitis, scleritis, uveitis, glaucoma, stye etc. Any fundus pathology like optic atropy, diabetic retinopathy, hypertensive retinopathy, papilledema etc; and patients with neck and shoulder discomfort, back pain are excluded.

\section{Study design}

Ten patients were randomly selected and treated by 'tarpana' with 'chandanadi ghrita'(4) once a day in the morning for 7 days. Later 'tarpana' was resumed for 
another 7 days. Similarly, this procedure was repeated for $3^{\text {rd }}$ and $4^{\text {th }}$ sittings.

\section{Follow up period}

Observations were done regarding the changes after the treatment once in 15 days for a period of 3 months.

\section{Assessment phase:}

Effect of the therapies was compared before and after the treatment on the basis of self formulated scoring scale to signs and symptoms in subjective and objective parameters.

\section{Subjective Parameters}

Eye strain, dry eyes, blurred vision, headache, redness and diplopia

\section{Objective Parameters}

Refractory changes - Snelen's chart assessment, Schirmer's Test, Tear Break up Time (TBUT), Rose Bengal staining.

\section{Parameters Gradation Index:}

1. Eye strain:

$$
\begin{aligned}
& 0 \text { - Absent } \\
& 1 \text { - Mild eye strain } \\
& 2 \text { - Moderate eye strain } \\
& 3 \text { - Severe eye strain. }
\end{aligned}
$$

2. Dryness:

$$
\begin{aligned}
& 0 \text { - No feeling of dryness. } \\
& 1 \text {-Mild dryness. } \\
& 2 \text {-Moderate dryness. } \\
& 3 \text { - Severe dryness. }
\end{aligned}
$$

3. Blurred vision:
0 - No blurrness
1 - Mild blurrness
2 - Moderate blurrness
3 -Severe blurrness

4. Headache:
0 - Absence of headache.
1 - Mild - Tolerable, negligible.
2 - Moderate - Constant, tolerable.
3 - Severe - Intolerable, Constant.

5. Redness:

$0-$ Absent.

1 - Discrete, thin vessels vascular network limited to P.C. \& fornix.

2 - Prominent vascular network involving peripheral part of B.C.

3 - Fiery red eye involving whole B.C. \& circum corneal zone.

6. Diplopia:
0 - Absent
1 - Mild - Transient diplopia
2 - Moderate - Diplopia in few direction of gazes
3 - Severe - Constant diplopia in all direction of gazes

7. Progressive refractory changes:

$0-6 / 6$
$1-6 / 9$
$2-6 / 12$

$$
\begin{aligned}
& 3-6 / 18 \\
& 4-6 / 24 \\
& 5-6 / 36 \\
& 6-6 / 60
\end{aligned}
$$

8. Schirmer's test:

0 - Level of wetting of tear strip above $15 \mathrm{~mm}$ in 5 minute.

1 - Level of wetting of tear strip above $10 \mathrm{~mm}$ $15 \mathrm{~mm}$ in 5 minute.

2 - Level of wetting of tear strip above $5 \mathrm{~mm}$ $10 \mathrm{~mm}$ in 5 minute.

3 - Level of wetting of tear strip at $1 \mathrm{~mm}-5 \mathrm{~mm}$ in 5 minute.

9. Tear break up time:

0 - The appearance of dry spots after $15 \mathrm{sec}$.

1 - The appearance of dry spot between 10-15 sec.

2- The appearance of dry spot between 5-10 sec.

3 - The appearance of dry spot within $5 \mathrm{sec}$.

10. Rose Bengal staining:

0 - No staining

1 - Pattern $\mathrm{C}$

2 - Pattern B

3 - Pattern A

\section{Assessment criteria:}

No improvement - $0(0)$

1 line improvement $-1(15 \%)$

2 lines improvement $-2(30 \%)$

3 lines improvement $-3(45 \%)$

4 lines improvement $-4(60 \%)$

5 lines improvement $-5(75 \%)$

6 lines improvement $-6(90 \%)$

\section{Results}

The observations and the results are tabulated as in Table no 1.

\section{Discussion}

\section{Discussion on Results}

To evaluate the effect of treatment on individual parameters, paired t-test was applied. Significance is accessed at 5\% level of significance. A null hypothesis has been stated that the results significance is at 0.05 . The obtained results are as shown below.

\section{Effect of therapy on individual parameter 1. Eye strain}

There was $85.106 \%$ of improvement in the subjective tiredness symptom of the eyes, with $t$ value 19.493 , the result was extremely statistically significant $(\mathrm{p}<0.0001)$.

\section{Eye strain- $\mathbf{8 6 . 1 1 \% ~ o f ~ i m p r o v e m e n t ~}$}

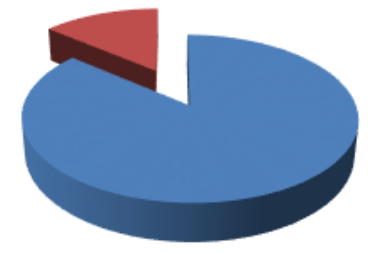


Table-1: Showing Individual study of the parameters

\begin{tabular}{|c|c|c|c|c|c|c|c|c|c|c|}
\hline \multirow{2}{*}{\multicolumn{2}{|c|}{ Parameters }} & \multicolumn{2}{|c|}{$\begin{array}{l}\text { Average } \\
\text { Difference }\end{array}$} & \multirow{2}{*}{$\begin{array}{l}\text { Dif- } \\
\text { ferenc } \\
\text { e } \\
\text { (d) }\end{array}$} & \multirow{2}{*}{$\begin{array}{l}\% \text { differ- } \\
\text { ence } \\
\% \mathrm{~d}\end{array}$} & \multirow[t]{2}{*}{ SD } & \multirow[t]{2}{*}{$\overline{\mathrm{SE}}$} & \multirow[t]{2}{*}{$\begin{array}{l}\mathrm{T} \text { value } \\
\mathrm{df}=19\end{array}$} & \multirow[t]{2}{*}{$\mathrm{P}$ value } & \multirow[t]{2}{*}{$\begin{array}{l}\text { Re- } \\
\text { mark } \\
\mathrm{s}\end{array}$} \\
\hline & & BT & AT & & & & & & & \\
\hline \multicolumn{2}{|l|}{ Eye strain } & 2.35 & 0.35 & 2 & 85.106 & 0.458831 & 0.102598 & 19.49359 & $<0.0001$ & H.S \\
\hline \multicolumn{2}{|c|}{ Blurred vision } & 1.5 & 0.5 & 1 & 66.66 & 0.324443 & 0.072548 & 13.78405 & $<0.0001$ & H.S \\
\hline \multicolumn{2}{|l|}{ Dryness } & 1.5 & 0.25 & 1.25 & 83.333 & 0.7163 & 0.16018 & 7.8036 & $<0.0001$ & H.S \\
\hline \multicolumn{2}{|l|}{ Redness } & 0.95 & 0.15 & 0.8 & 89.4737 & 0.48936 & 0.109424 & 7.767925 & $<0.0001$ & H.S \\
\hline \multicolumn{2}{|l|}{ Headache } & 1.45 & 0.55 & 0.9 & 62.06 & 0.648886 & 0.145095 & 6.892024 & $<0.0001$ & H.S \\
\hline \multicolumn{2}{|l|}{ Diplopia } & 0.15 & 0 & 0.15 & 100 & 0.366348 & 0.081918 & 1.831104 & $>0.05$ & N.S \\
\hline \multirow{2}{*}{$\begin{array}{l}\text { Refractory } \\
\text { changes }\end{array}$} & \multirow{2}{*}{$\begin{array}{l}\text { RE } \\
\mathrm{LE}\end{array}$} & 2.1 & 0.9 & 1.2 & 57.142 & 1.23969 & 0.277204 & 4.328941 & $<0.05$ & $\mathrm{~S}$ \\
\hline & & 2.15 & 0.8 & 1.35 & 62.7907 & 1.386969 & 0.310136 & 4.352932 & $<0.0001$ & H.S \\
\hline \multirow[t]{2}{*}{ Schirmer's } & \multirow{2}{*}{$\begin{array}{l}\text { RE } \\
\mathrm{LE}\end{array}$} & 1.05 & 0.25 & 0.8 & 76.1904 & 0.523148 & 0.11698 & 6.838803 & $<0.0001$ & H.S \\
\hline & & 0.95 & 0.35 & 0.6 & 63.1578 & 0.502625 & 0.11239 & 5.338539 & $<0.0001$ & H.S \\
\hline \multirow[t]{2}{*}{ TBUT } & \multirow{2}{*}{$\begin{array}{l}\text { RE } \\
\mathrm{LE}\end{array}$} & 0.7 & 0.2 & 0.5 & 71.4285 & 0.606977 & 0.135724 & 3.683942 & $<0.05$ & $\mathrm{~S}$ \\
\hline & & 0.65 & 0.2 & 0.45 & 69.23 & 0.604805 & 0.135239 & 3.327453 & $<0.05$ & $\mathrm{~S}$ \\
\hline \multirow[t]{2}{*}{ RBS } & \multirow{2}{*}{$\begin{array}{l}\mathrm{RE} \\
\mathrm{LE}\end{array}$} & 0.45 & 0.25 & 0.2 & 44.4444 & 0.410391 & 0.091766 & 2.179449 & $<0.05$ & $\mathrm{~S}$ \\
\hline & & 0.45 & 0.2 & 0.25 & 55.5555 & 0.444262 & 0.0993 & 2.516611 & $<0.05$ & $\mathrm{~S}$ \\
\hline
\end{tabular}

\section{Blurred vision}

There was a $66.66 \%$ improvement in the symptom, with $t$ value 13.38 , the result was extremely statistically significant $(\mathrm{p}<0.0001)$.

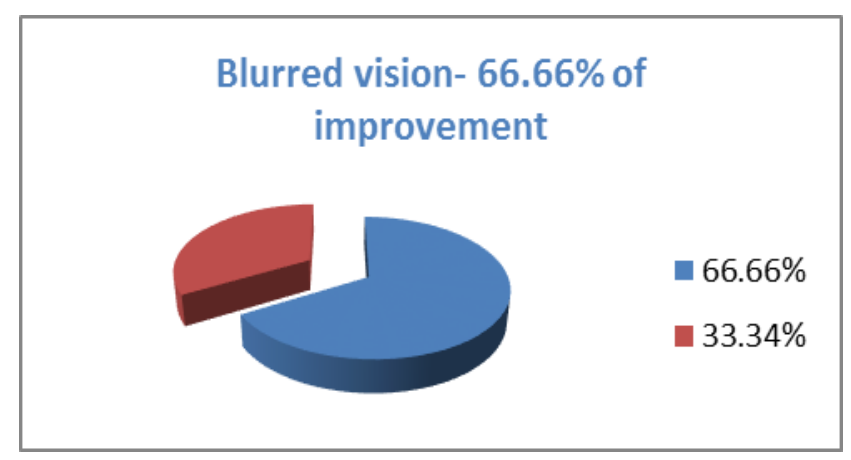

\section{Dryness}

There was an $83.33 \%$ improvement in the symptom, with t value 7.8036 , the result was highly statistically significant $(\mathrm{p}<0.0001)$.

\section{Dryness- $\mathbf{8 3 . 3 3 \%}$ of improvement}

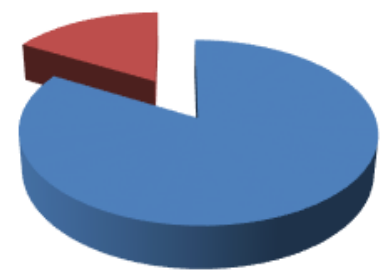

\section{Redness}

There was $89.47 \%$ improvement in the symptom, with $\mathrm{t}$ value 7.767 , the result was extremely statistically significant at $(\mathrm{p}<0.0001)$

\section{Redness- $89.47 \%$ of improvement}



\section{Headache}

There was a $62.06 \%$ of improvement in the sign, with $t$ value 6.892 , the result was statistically extremely significant $(\mathrm{p}<0.0001)$.

Headache- $62.06 \%$ of improvement

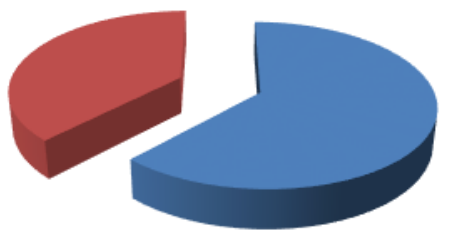

$62.06 \%$

$37.94 \%$ 


\section{Diplopia}

There was a $0 \%$ improvement in the symptom, with $\mathrm{t}$ value 1.83 , the result was not statistically significant $(\mathrm{p}<0.0001)$.

\section{Diplopia- $\mathbf{0 0 . 0 0 \% ~ o f ~ i m p r o v e m e n t ~}$}

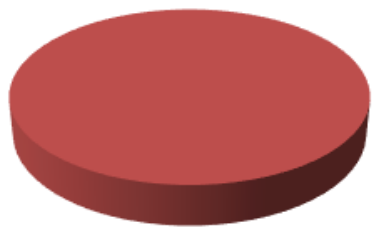

$=0.00 \%$

$100.00 \%$

\section{Progressive refractory changes $\mathbf{R E}$}

There was a $61.9 \%$ improvement in the feature, with $\mathrm{t}$ value 4.6113, the result was extremely statistically significant $(\mathrm{p}<0.0001)$.



\section{Progressive refractory changes $\mathbf{L E}$}

There was a $72.09 \%$ improvement in the feature, with $t$ value 5.263 , the result was extremely statistically significant $(\mathrm{p}<0.0001)$.

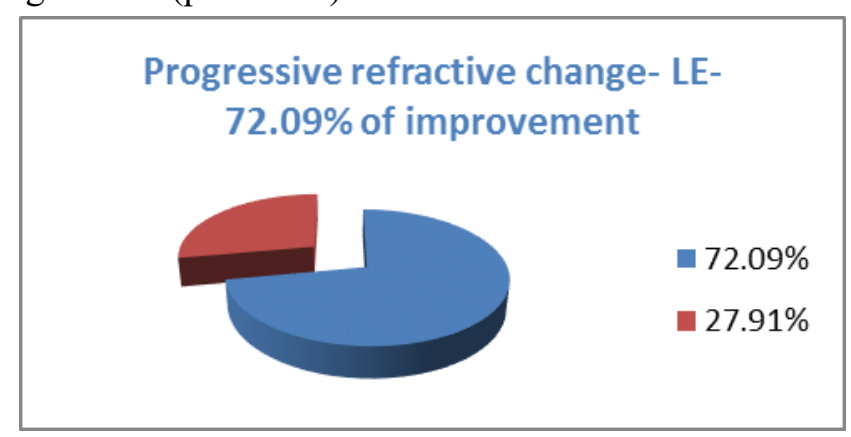

\section{Schirmer's RE}

There was a $76.19 \%$ improvement in the feature, with $\mathrm{t}$ value 6.8388 , the result was extremely statistically significant $(\mathrm{p}<0.0001)$.

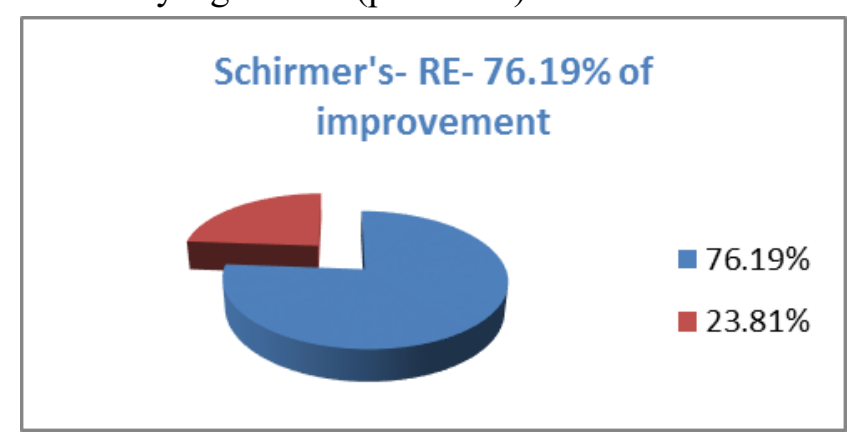

\section{Schirmer's LE}

There was a $63.15 \%$ improvement in the feature, with $t$ value 5.338 , the result was extremely statistically significant $(\mathrm{p}<0.0001)$.



\section{TBUT- RE}

There was a $71.42 \%$ improvement in the feature, with $t$ value 3.683 , the result was

\section{TBUT- RE- 71.42\% of improvement}

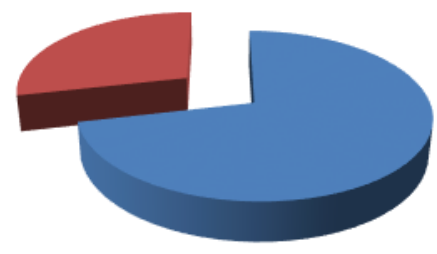

$71.42 \%$

$28.58 \%$

\section{TBUT- LE}

There was a $69.23 \%$ improvement in the feature, with $\mathrm{t}$ value 3.3274 , the result was statistically very significant $(\mathrm{p}<0.0035)$

\section{TBUT- LE- $69.23 \%$ of improvement}

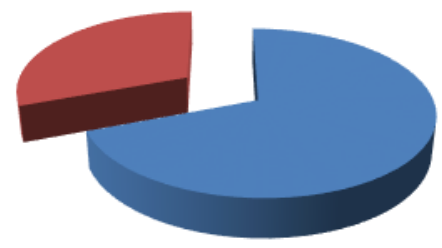

$69.23 \%$

- $30.77 \%$

\section{Rose Bengal staining - RE}

There was a $44.44 \%$ improvement in the feature, with $\mathrm{t}$ value 2.1794 , the result was statistically significant $(\mathrm{p}=0.042)$

\section{Rose Bengal staining- RE- $44.44 \%$ of improvement

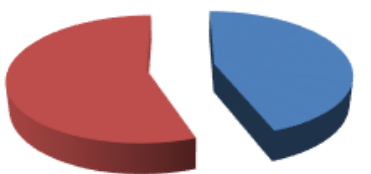




\section{Rose Bengal staining - LE}

There was a $55.55 \%$ improvement in the feature, with $t$ value 2.5166 , the result was statistically significant $(\mathrm{p}=0.0210)$

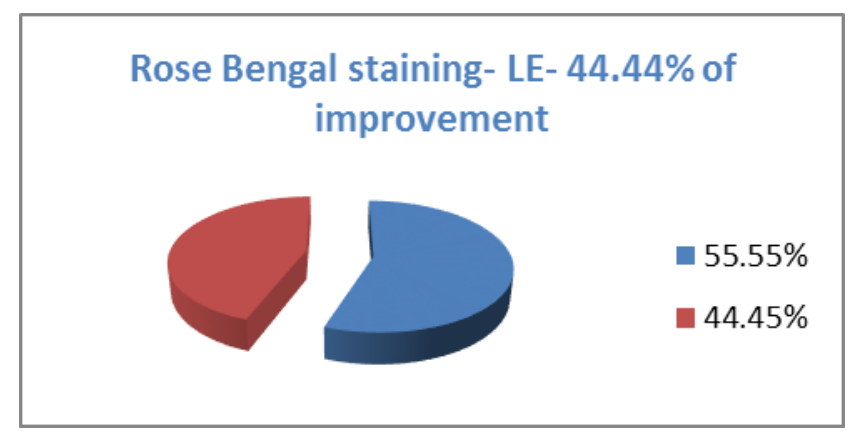

\section{Discussion}

During the post treatment period, only three out of 10 of treated patients had recurrence of the complaints. Therefore treatment of "computer vision syndrome' can be managed with 'chandanadi ghrita tarpana' alone.

So, this pilot study reflects the true efficaciousness of 'chandanadi ghrita tarpana' when used judiciously in selected cases of 'computer vision syndrome'.

The 'chakshushya' action of the ingredients of 'chandanadi ghrita' and the soothing influence of this medicated ghee delivers the desired results in 'computer vision syndrome'.

Tarpana done here with 'chandanadi ghrita' forms an occlusive film over the surface of the eyeball and improves the composition of tear film by enhancing the mucin and aqueous layers.

It prevents frictional damage to the ocular surfaces secondary to lid movement or extra ocular movements. It acts by retaining fluid and maintaining hydration of the ocular surface.
It is effective in reducing evaporation rate in patients with computer vision syndrome. Prevents desiccation from corneal tear film, reduces burning sensation in patients with dryness.

It also reduces reflex tearing and reduces the need for artificial tears and warm compressors. The nourishing property and 'chakshushya guna' of 'ghrita', 'yashtimadhu',and 'daruharidra' helps in relieving 'vata prakopaka' symptoms like eye strain, headache, diplopia, dryness and inability to focus near objects.

\section{Conclusion}

CVS is a new occupational hazard seen in computer users, hence cannot be expected to be in Ayurvedic period, which is going to be a key health threat in near future.

This pilot study of 'chandanadi ghrita tarpana' shows encouraging results in the improvement of different symptoms of 'computer vision syndrome'.

As the results are encouraging, this study can be taken up for further large-scale clinical study to reestablish the efficacy of 'chandanadi ghrita tarpana' in 'computer vision syndrome'.

\section{References}

1. Loh KY, SC Reddy, Understanding and Preventing Computer vision syndrome; Malaysian Family Physician 2008; Volume 3. Number 3.

2. Grant A: The computer user's syndrome. J.Am.Optom.Asso:1987; 58:892-901.

3. Vaidya Mahendra Simha Arya, Sahasrayoga; Dr. D.V.Pandit Rao - Translator, Kendriya Ayurveda and Siddha Anusandhana Parishad, New Delhi; 1999. P. 305.

4. Sushruta, Sushruta samhita, Nibandha sangraha of Dalhanacharya - commentary, Vaidya Yadavji Trikamji Acarya- editor, Chaukhamba Surabharati Prakashan, Varanasi; 2008. P. 824 